\title{
Concepts for the Reduction of Discomfort Generated by Prolonged Static Posture during Driving Task, Part I: Basic Concepts and Theories
}

\section{Abdelkerim $\mathrm{R}^{*}$ \\ Department of Industrial Engineering, Mohammadia engineering school, Rabat, Morocco}

*Corresponding author: Abdelkerim Rhimi, Department of Industrial Engineering, Mohammadia engineering school, Lot Rhimi $\mathrm{N}^{\circ} 6$ Lbirjdid Provincy Eljadida, Rabat, Morocco, Tel: +212640270650; Email: abdelkerim-rhimi@hotmail.com

\section{Research Article}

Volume 2 Issue 3

Received Date: May 08, 2018

Published Date: May 22, 2018

DOI: $10.23880 /$ eoij-16000148

\section{Abstract}

Several researches have been reported in the last decade to improve comfort (reduce discomfort) of cars interior, especially car seats. Designing a comfortable car seat was and still is the problem of designers and ergonomists. Despite the huge number of researches conducted to reduce discomfort and to improve comfort feeling during driving task, hardly any solution was given to reduce discomfort of the Prolonged Static Posture (PSP) while driving. In this study, a questionnaire was completed by drivers working intensively on vehicles and spending several hours per day driving, to investigate discomfort caused by the driving activities and to get their opinion about aspects that need to be improved in order to design more comfortable car seat. The results show that almost every driver complains of the PSP symptoms after a long driving. In order to find the best possible solution for this problem, participatory and axiomatic design methodologies were employed in this study.

Relevance to Industry: This paper may assist the improvement of design aspect of the car seat that consequently leads to reduction of the musculoskeletal injuries caused by the Prolonged Static Posture during driving task.

Keywords: Prolonged Static Posture; Car Seat Design; Axiomatic Design; Participatory Design; Discomfort

\section{Introduction}

Various disadvantages caused by the sitting posture while driving; the long duration of the sitting, the activities undertaken and the quality of furnishings influence the risk of developing low back pain [LBP]; which can be a risk symptom for the musculoskeletal disorder. A study on the factors of aggravation of chronic venous insufficiency in patients with different clinical severities revealed that prolonged sitting posture, with little standing postures, is associated with increased severity of disorders [1]. A European study has also shown that $74 \%$ of respondent's cashiers, who work in a sitting posture, consider their working position uncomfortable and $60 \%$ of them report having LBP [2]. Magora also found that both too much sitting and standing were related to a high incidence of LBP [3]. Wilke, et al. demonstrated that lumbar lordosis decreases 


\section{Ergonomics International Journal}

in sitting posture due to the flexion of the trunk, and the resulting compression of the intervertebral discs, the continuation of this posture for a long period results in dehydration of the disc and its progressive degeneration, this condition has been showed in the literature as harmful and as a potential for a variety of injury mechanisms [4-7].

This article aims to find a practical solution of discomfort generated by the static position during a prolonged driving task. 52 respondents participate in a survey to investigate the discomfort caused by the driving activities and to ask the participants about their design suggestions that could reduce this problem. Two main activities were undertaken in this study to explore the design parameters of the car seat. The following research activities are: One: Investigating the major attributes that drivers are looking for in car interior seats through a survey, and gather information about the source problems which conducted to discomfort. Two: Applying Axiomatic Design for designing a robust car seat based on the data collected and analysed in activity 1 .

The 6stages for the participatory design were employed as a methodology for evaluation of the design selected. It is noted that no research has been report educing both axiomatic and participatory design approaches in ergonomic problem resolution. To create a design of car seat that is acceptable from the ergonomics point of view, Suh [8] stated that the functional requirements (FRs) and constraint related to ergonomics issues must be identified and defined from the beginning of the design process, where the design parameter (DPs) must be determined to satisfy the FRs independently.

Participatory design focuses on an ergonomic strategy that can be applied in different ways in different fields of ergonomics. Participatory design is the discipline that studies how different parties should be involved in a design process; it is the adaptation of the environment to the human (i.e., ergonomics) with the involvement of the proper persons in question (participants) [9]. The aims of a participatory design process are to allow users to have a large amount of input into product design. Users have tacit knowledge as a result of their high level of familiarity with a workplace or piece of equipment, which means that they will be more aware of any problems experienced and more able to give advice regarding design modifications [10]. While Axiomatic Design (AD) provides a scientific basis and logical and rational thought process for the ergonomics design [11]. This method constitutes a formalized methodology that can be used to represent a variety of design problems [12].

\section{Research Method}

\section{Participatory Design and Axiomatic Design Approaches}

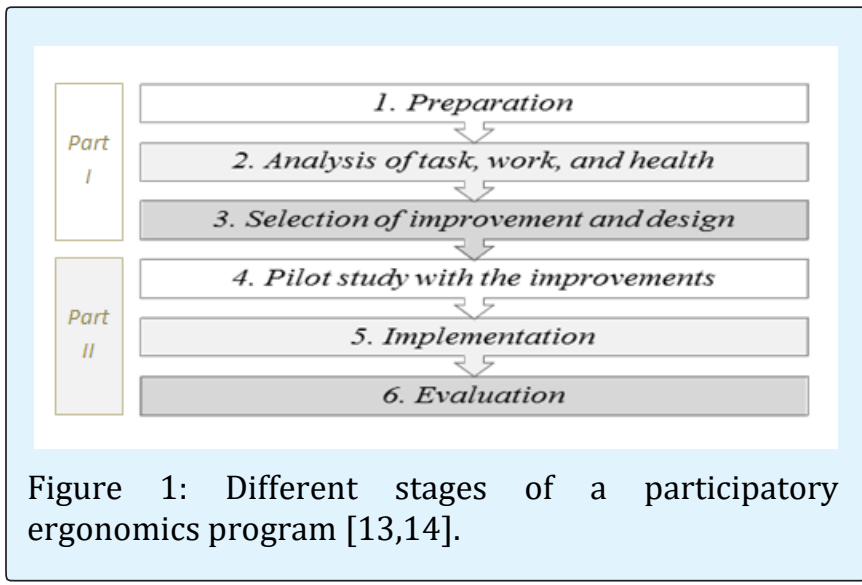

A six-step approach (Figure 1) was utilized to find the best possible design that could decrease the discomfort in car seats, all participant progress step-by-step toward the end result. Axiomatic design was applied in section three of participatory design (selection of improvement and design) providing logical and rational thought processes and design tools in the early stage of the design.

The first three steps of participatory design are introduced in this article (first part). The remaining steps are discussed in second part study "Concepts for the reduction of the discomfort generated by the prolonged static posture during the driving task, part II: Experiments and validations" [15].

$>\quad$ Step 1-Preparation: Drivers, are aware of the problem, our role is to stimulate discussions to allow the drivers to formulate improvements. Starting the project will be difficult because the attitude of potential participants may be indifferent. However, each Participant was informed about the project. The aim of the project is to evaluate their opinion about discomfort of the car seat, and benefit from their experience to design more comfortable car seat.

A questionnaire was developed and deployed to respondents (drivers) to get their opinion about the aspects that need to be improved in car seats, it consists of two parts: Part one where an evaluation of the drivers' comfort-satisfaction was made. : Part two consist of an 


\section{Ergonomics International Journal}

evaluation of the four aspects that leads to discomfort in car's interior "Physiological aspects, psychological aspects, environmental aspects and postural aspects".

The sample size required at $95 \%$ of the accepted confidence level, and a maximum proportion of peoples' behavior $50 \%$, and with a margin of error $14 \%$ is 49 samples. 52 questionnaires have been accepted as valid feedback responses. It means that number of samples received has fulfilled the minimum requirement of valid sample size. Descriptive non-parametric statistical analysis was also applied in this study.

\section{$>\quad$ Step 2-Analysis of Task, Work and Health: In} this stage, the main discomfort causes and musculoskeletal risks were defined. Those dentitions were based on data collection; literature review; and previous studies. The effects of the PSP during driving task on the perceive discomfort, and biomechanical back stress were investigated. Ten healthy subjects between 25 and 30 years of age, with at least 3 years of driving experience, were observed before and after a driving task. A questionnaire was giving to respondents before and directly after 2 hours of driving task while the drivers could feel the discomfort in their entire body. Using local postural discomfort (LPD), the drivers had to rate their perceived discomfort on a category ratio scale ranging from no discomfort (score 0) to extreme Discomfort (score 5 ). The statistical analysis was initially performed by the Wilcoxon signed-rank test for paired observations ( $p<$ 0.05 )

Step 3-Selection of Improvement and Design: Group sessions were planned to develop new ideas for improvements using Axiomatic design principals. To gather information about "what we want to achieve" and to examine the question from a larger macro-ergonomic perspective, a focus group was made with ergonomics to discuss each functional requirements that need to be introduced in the design, where each of the FRs should be satisfied by only one DP. The choice for the axiomatic approach is justified by many ways. One of them is the fact that the creative process during conceptual design has not been properly aided by traditional methods. The axiomatic approach aids the creative process, because it gives means to evaluate projects by means of design axioms. Selecting "good" and "bad" projects; the project team can spend more time searching and developing new solutions. Also, through the mapping of relations between functions and solutions, foreseen by the axiomatic approach, stimulus occurs to get creative solutions, because the challenge of searching for uncoupled or decoupled solutions is to be met. Another great advantage of the axiomatic approach is the use of design axioms as decision criteria for design, still in the conceptual phase, where the decisions reflect broad consequences in the whole product life cycle [16].

In this paper axiomatic design used to interplay between "what we want to achieve" and "how we achieve it." Trying to obtain what we want to achieve through appropriate interplay between both sides. The engineering sequence can be classified into four domains as illustrated in Figure 2. Customer attributes (CAs) are delineated in the customer domain. In other words, CAs is the customer needs. CAs are transformed into functional requirements (FRs) in the functional domain. FRs is defined by engineering words. This is equivalent to "what we want to achieve." FRs are satisfied by defining or selecting design parameters (DPs) in the physical domain. Mostly, this procedure is referred to as the design process. Production variables (PVs) are determined from DPs in the same manner.

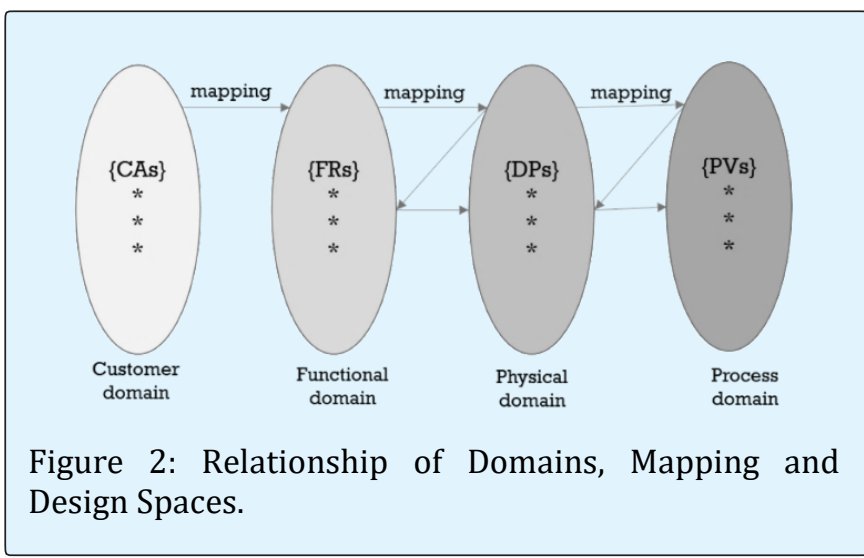

The aspects of the next domain are determined by the relationship between the two domains, and this process is called mapping. A good design process means an efficient mapping process. In the mapping process from domain to domain, Suh [11] recommends to be done within a "solution-neutral environment". This means that the mapping must be defined without ever thinking about something that has already been designed. Once the CAs had been identified and defined, these attributes must be translated into FRs and map them into a specific DPs satisfying the FRs and also into PVs that can satisfy the DPs specified. This process began as one to many processes in a hierarchy way, that it is also called zigzag or decomposition process, by referring to two axioms: the independence axiom (axiom 1) and the information axiom(axiom2). The axiom 1: states that an optimal 
design always maintains the independence of FRs, in an acceptable DPs and FRs are related in such a way that specific DP can be adjusted to satisfy its corresponding FR without affecting other FRs Scheme1 (a). This mapping process can be formulated mathematically as [11].

$$
\{F R\}=[A]\{D P\}(a)
$$

Matrix $[\mathrm{A}]$ is called a design matrix. The characteristics of matrix A determine if the Independence Axiom is satisfied, if the design matrix is a diagonal matrix, as shown in Scheme1 (b) it is an uncoupled design. Because each DP can satisfy a corresponding FR, the uncoupled design perfectly satisfies the Independence Axiom. When the design matrix is triangular as shown in Scheme1 (c), the design is a decoupled design. A decoupled design satisfies the Independence Axiom if the design sequence is correct. When a design matrix is neither diagonal nor triangular, "Scheme1 (d)" the design becomes a coupled design. In a coupled design, no sequences of DPs can satisfy the FRs independently. Therefore, an uncoupled or a decoupled design satisfies the Independence Axiom, and a coupled design does not.

$$
\begin{aligned}
& {\left[\begin{array}{l}
F R_{1} \\
F R_{2} \\
F R_{3}
\end{array}\right]=\left[\begin{array}{ccc}
A_{11} & 0 & 0 \\
0 & A_{22} & 0 \\
0 & 0 & A_{33}
\end{array}\right]\left[\begin{array}{l}
D P_{1} \\
D P_{2} \\
D P_{3}
\end{array}\right](\mathrm{b})} \\
& {\left[\begin{array}{l}
F R_{1} \\
F R_{2} \\
F R_{3}
\end{array}\right]=\left[\begin{array}{ccc}
A_{11} & 0 & 0 \\
A_{21} & A_{22} & 0 \\
A_{31} & A_{32} & A_{33}
\end{array}\right]\left[\begin{array}{l}
D P_{1} \\
D P_{2} \\
D P_{3}
\end{array}\right](\mathrm{c})} \\
& {\left[\begin{array}{l}
F R_{1} \\
F R_{2} \\
F R_{3}
\end{array}\right]=\left[\begin{array}{lll}
A_{11} & A_{12} & A_{13} \\
A_{21} & A_{22} & A_{23} \\
A_{31} & A_{32} & A_{33}
\end{array}\right]\left[\begin{array}{l}
D P_{1} \\
D P_{2} \\
D P_{3}
\end{array}\right](\mathrm{d})}
\end{aligned}
$$

Scheme 1: Types of design matrix (b) uncoupled, (c) decoupled (d) coupled design.

\section{Results and Discussion}

\section{Results of Step 1(Preparation)}

The defined goal of the project was clear -reducing discomfort in the car seat and improve comfort as well. The questionnaire has generated a large amount of input of the discomfort leading causes. According to participants, the prolonged sitting posture was the most relevant problem, and then comes the vibration and the stress (Figure3).

The second part of the questionnaire was made to evaluate the customer's needs in cars seats, by evaluating the leading causes of discomfort in four aspects: (physiological, psychological, environmental and postural aspects), a rating for each aspect was made to evaluate the discomfort leading causes. The result shows that the physiological aspect had the highest rating of discomfort's leading causes in the car's interior according to participants.

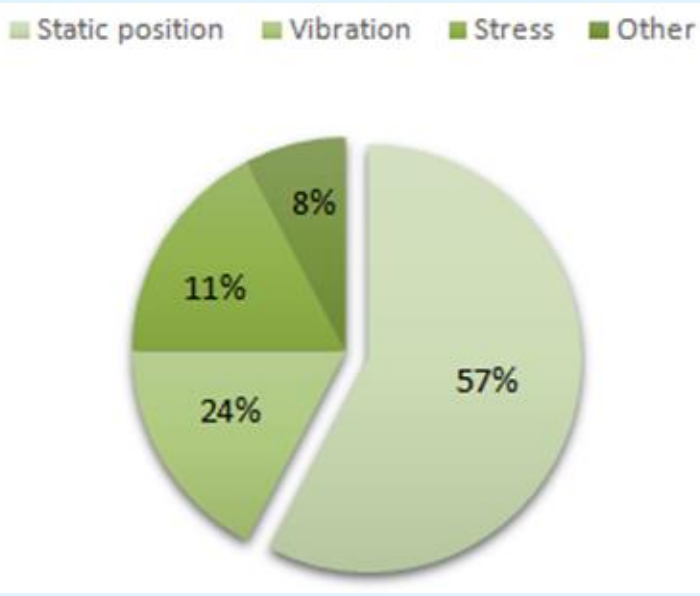

Figure 3: Result of evaluation the discomfort leading causes according to 52 professional drivers.

The results of evaluating the Physiological discomfort of 52 respondents (Figure 4) show that the majority of the participants suffer from back pain, neck pain, heavy foot, and joint locking after the driving task. In addition, the majority of drivers consider their working posture, as uncomfortable (Figure 5) .These results are consistent with many research studies that indicate the need for a greater understanding of the discomfort leading causes during driving task.

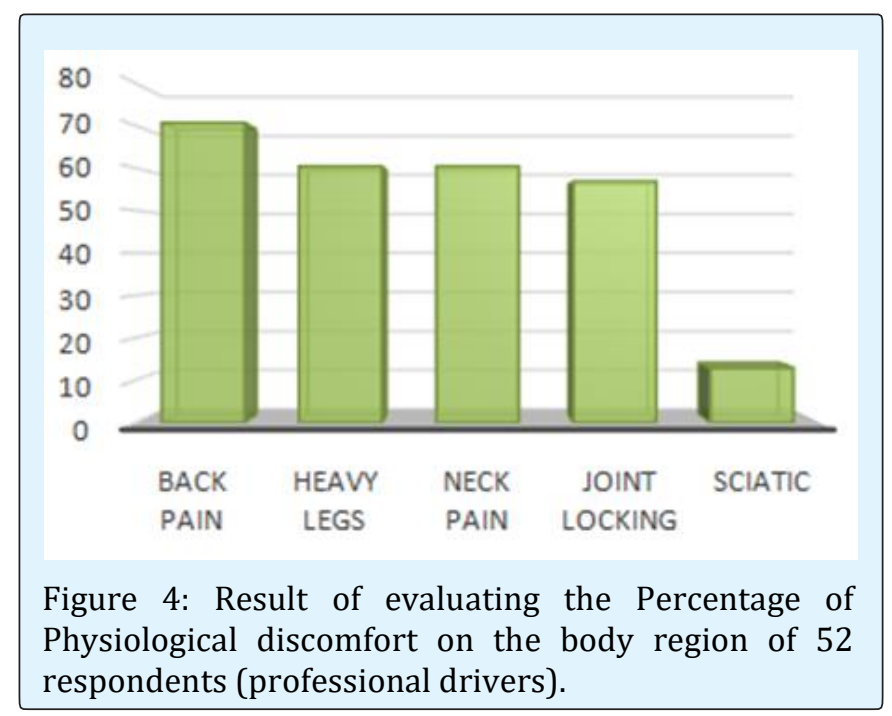




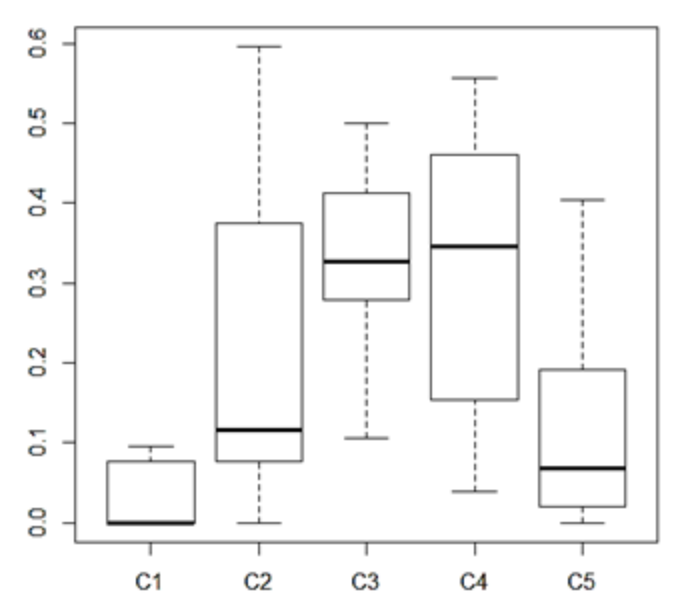

Figure 5: Result of evaluating the general body discomfort according to 52 respondents using a scale ranging from $\mathrm{C} 1$ (no discomfort) to $\mathrm{C} 5$ (extreme discomfort).

\section{Results of Step 2 (Analysis of Task, Work and Health)}

The Result of the LPD Scale, before and after spending
2 hours in driving task shows an increase in the level of discomfort, this effect was significant for the neck, the buttock, the legs, the elbow, and the ankle, the local perceived discomfort in lower back was influenced most. Discomfort in the other part also increased, but the effect did not reach significance (Table1, Figure 6).

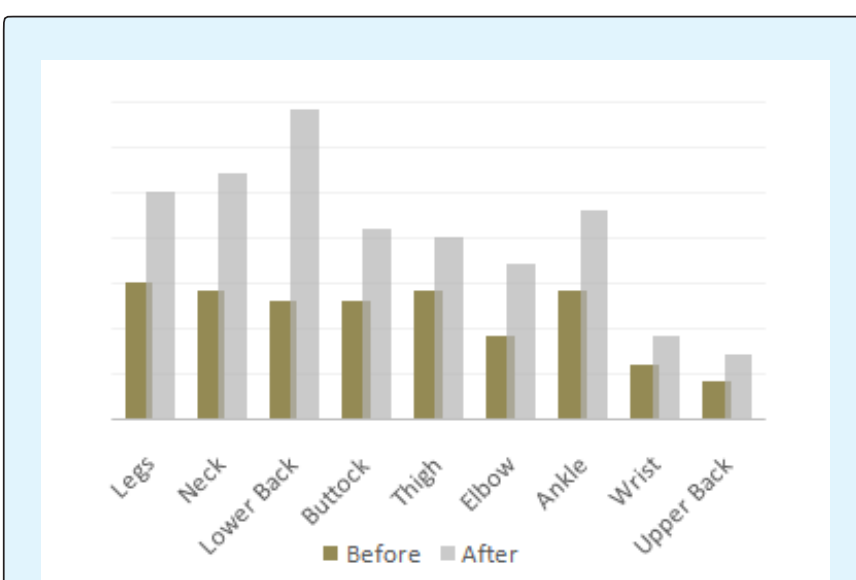

Figure 6: The LPD in different body regions before and after a 2 hours of driving task $(n=10)$.

\begin{tabular}{|c|c|c|c|c|c|c|c|c|c|}
\hline & Neck & Lower Back & Buttock & Thigh & Upper Back & Legs & Elbow & Ankle & Wrist \\
\hline Difference & $1.3^{*}$ & $2.1^{*}$ & $0.8^{*}$ & 0.6 & 0.3 & $1^{*}$ & $0.8^{*}$ & $0.9 *$ & 0.3 \\
\hline Z-value & $-2,22$ & $-2,57$ & $-2,53$ & $-1,73$ & $-1,13$ & $-2,49$ & $-2,30$ & $-2,49$ & $-1,13$ \\
\hline P-value* &, 026 &, 010 &, 011 &, 083 &, 257 &, 013 &, 021 &, 013 &, 257 \\
\hline \multicolumn{8}{|c|}{ * Significant; $p<0.05$ ilcoxon signed-rank test, n=10 } \\
\hline
\end{tabular}

Table 1: Mean Difference in Local Perceived Discomfort before and after a driving task.

The main problem identified by the drivers appeared to be the PSP during driving task. This issue was confirmed by many research studies. A study made by Kelsey and Hardy [17] shows that the People who spend a large amount of time driving do have higher incidences of lowback pain and disc herniation than those who spend less time driving. Sitting posture can lead to many complications of a general nature, such as discomfort or fatigue, but also diseases of the musculoskeletal system (at the spine and lower limbs), chronic venous insufficiency, deep vein thrombosis, obesity [18].
Winkel et al., and Pottier, et al. [19,20] demonstrated that the angle at the knee decreases venous return, especially when there is compression in the popliteal fossa. This slowing of the blood flow can cause an increase in the volume of the foot when the legs remain in this position for a long period. Pottier, et al. had also observed that $60 \%$ of the increase in the volume of foot occurred after only 15 minutes of sitting [20]. These data on the increase in the volume of fluid in the lower legs were confirmed by studies Sun, Weddell, and Winkel, et al. who conclude that the sitting posture gives swelling in the legs, 


\section{Ergonomics International Journal}

especially when it is difficult to move the legs [21-23]. Maintaining a static posture, including sitting posture $[7,24]$, hamper the distribution and nutritional deficiency, which can leads to disorders that of the intervertebral discs. In 2004, a study by Van Dieen and Nussbaum recalls that sitting, flexion of the trunk on the thigh causes an increase in force generated by the erector spinal muscles and other core muscles to support the trunk [25].

A Spanish study found that a Lordosis curve preserved with pelvis tilted forward and low mobility is the main cause of increased discomfort in the lumbar spine [25]. The decrease of the lumbar curvature imposed by the sitting posture, increases the bending of the head compared to the standing posture $[27,28]$. And many other research studies show that the prolonged sitting posture could cause many complications in the entire body. The goal of next step is to find the best possible design that could reduce musculoskeletal injuries (by reducing discomfort) causes by the PSP during driving task. In the next stage, the solution of this problem was discussed with ergonomics in a focus group.

\section{Results of Step 3 (Selection of Improvement and Design)}

The first step of the axiomatic design approach is to obtain a complete list of Customer Needs, the result of the questionnaire made earlier produced several customers' attributes of the car's interior design. These are:

$\mathrm{CA}_{1}$ : Reduce physiological discomfort while driving" 55\%

$\mathrm{CA}_{2}$ : Reduce psychological discomfort while driving 39"

$\mathrm{CA}_{3}$ : Reduce postural discomfort while driving" 43.33\%

$\mathrm{CA}_{4}$ : Reduce environmental discomfort while driving" $52.5 \%$

After discussion, the first customer attributes $\mathrm{CA}_{1}$ "that was most relevant", was considered further in this study. The corresponding functional requirement that can satisfy the $\mathrm{CA}_{1}$ should be: $\mathrm{FR}_{1}$ :"Minimize physiological symptoms while driving".

To achieve the $\mathrm{DP}_{1}$, the $\mathrm{FR}_{1}$ must be decomposed in more detail by a zigzagging process and according to a hierarchical structure. The corresponding DPs are identified in the same hierarchical structure until the DPs are sufficiently detailed to be implemented. The decomposition process of $\mathrm{FR}_{1}$ produces a second level of FR consisting of four functional requirements. They are as follows:
$\mathrm{FR}_{11}$ : Reduce the exposure to the static posture while driving;

$\mathrm{FR}_{12}$ : Decrease mechanical effort on the body while driving;

$\mathrm{FR}_{13}$ : Adjust the lumbar support position of the car seat;

$\mathrm{FR}_{14}$ : Adjust the seat position.

The four design activities above must be specified in more detail FRs in order to develop a good design where each of the FRs should be satisfied by only one DP. The one to one relationship between FRs and DPs is called an uncoupled design.

$\mathrm{FR}_{111}$ : Provide a dynamic and regular adjustability of the Backrest angle while driving;

$\mathrm{FR}_{112}$ : Provide a dynamic and regular adjustability of the Lumbar support prominence while driving;

$\mathrm{FR}_{121}$ : Reduce the effort while controlling the vehicle speed;

$\mathrm{FR}_{122}$ : Decrease the exposure to inertia forces on the body;

$\mathrm{FR}_{123}$ : Decrease the exposure to inertia forces on the neck;

$\mathrm{FR}_{131}$ : Adjust the vertical position of the lumbar support;

$\mathrm{FR}_{141}$ : Satisfy the easy reach to steering wheel;

$\mathrm{FR}_{142}$ : Satisfy the easy reach to pedals.

The relationship is defined by a zigzagging process between the functional and physical domains. This decomposition process continues until the leaf (bottom) level is reached (Figure 7).

The corresponding third level DP to satisfy the third level independence FR can be developed as follows:

$\mathrm{DP}_{111}$ : $15-35^{\circ}$ regular swift movement with lower variation frequency;

$\mathrm{DP}_{112}$ : Dynamic and regular adjustability 0 to $50 \mathrm{~mm}$ prominence with lower variation frequency;

$\mathrm{DP}_{121}$ : velocity regulator device;

$\mathrm{DP}_{122}$ : Seat design against lateral movement due to inertia forces;

$\mathrm{DP}_{123}$ : Specific neck support design against inertia forces;

$\mathrm{DP}_{131}$ : vertical adjustability $100-200 \mathrm{~mm}$ above the $\mathrm{H}$ point;

$\mathrm{DP}_{141}$ : Manual seat adjustment -back rest angle $35^{\circ}$ recommended Elbow angle 120;

$\mathrm{DP}_{142}$ : Recommended knee angle 95-135. 


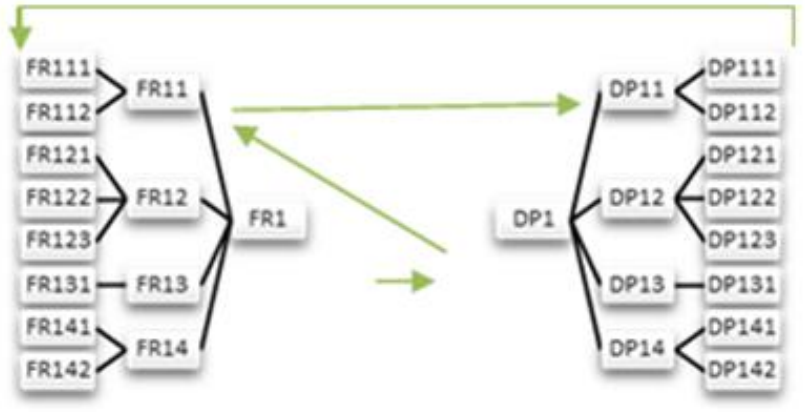

Figure 7: Hierarchical structures and decomposition of functional requirements (FRs) and design parameters (DPs).

The $\mathrm{DP}_{111}$ recommendation for 15 - to 35 - degree recline angle is consistent with the Rebiffé [29] recommendation and the EMG-based recommendations of Andersson, et al. [30] $\left(20-30^{\circ}\right.$ recline angles). $10^{\circ}$ was added to recommendation in $\mathrm{DP}_{111}$ to allow more bending of the back (allow more movement) and produces a greater reduction in back muscle activity.

The important aspect in car-design is the safety of the driver, driver should not be aware of the change in posture (movement) while driving, thus, driver safety will be an insistent constraint, for that reason the variation frequency must be extremely small (The movement frequency will be tested in further article (part II)).

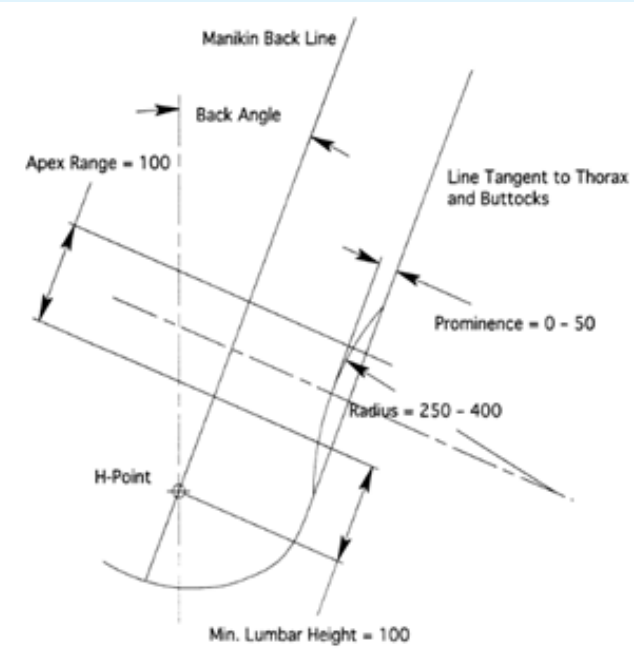

Figure 8: Schematic illustration of lumbar support recommendations (dimensions in $\mathrm{mm}$ ).
Reed et al. [31,32] found that spine postures observed in a long-term driving simulation did not conform to a prominent, convex lumbar support. These observations indicate the need for a greater understanding of how people respond posturally to changes in support. Current lumbar support specifications in $\mathrm{DP}_{112}$ and $\mathrm{DP}_{131}$ tend to be prescriptive, in that they are intended to support postures that have been identified as physiologically desirable. Understanding of how sitters interact dynamically with the seat contour could be both physiologically desirable and subjectively preferred. Figure 8 present the schematic illustration of lumbar support recommendations [33].

The driver's foot orientation can vary considerably while still maintaining control of the accelerator pedal. Currently, vehicle interior design tools (e.g., the H-point manikin and the 2-D "Oscar" template) do not consider these variations in posture. However, there may be important comfort implications of allowing such motion, the need of the $\mathrm{DP}_{121}$ is important in this case, the design may avoid many complication in the joint ankle and reduce the discomfort when the device is activated.

The inertia forces due to acceleration and deceleration present certain risks for the driver's neck. For that reason the $\mathrm{DP}_{122}$ and $\mathrm{DP}_{123}$ are the particular design which could reduce that risk. Nevertheless, the recent car seat design still developing head rest that could influence negatively the driver comfort. The head rest design was built for security measurement in case of a sudden behind choc. Thus, the need of a new design that could give the driver more liberty in moving his head while driving will be presented in the $\mathrm{DP}_{123}$.

The recommendation in $\mathrm{DP}_{141}$ is inspired from the Rebiffé recommendation for the Elbow angle. The knee angle is an important determinant of comfort. Rebiffé recommends that the angle not exceed 135 degrees. When the knees are extended, tension can develop in the hamstring muscles in the back of the thigh. Because these muscles are attached both below the knee and above the hip joint [34]. If the pelvis is forced to rock rearward because of tension in the hamstrings, then a lumbar lordosis is difficult to obtain without extreme seat recline angles. Thus, the $\mathrm{DP}_{142}$ is an important factor to consider in the seat design specification. The House of Quality Matrix gives the possibility to link each relationship between the Functional requirements and design parameters, it allow to 1- show the correlations between the "what and how" 2-manage all correlations between the how (Table 2). 
- Matrix

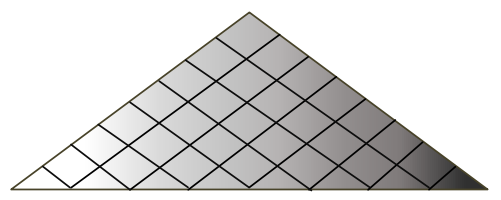

\begin{tabular}{|c|c|c|c|c|c|c|c|c|}
\hline Design Parmetres & 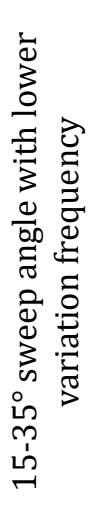 & 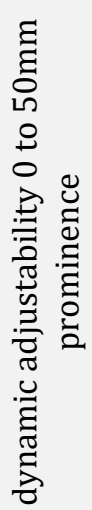 & 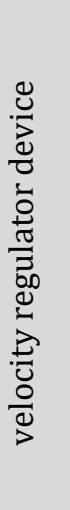 & 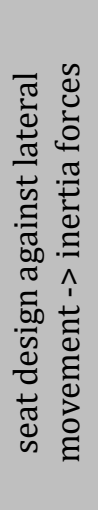 & 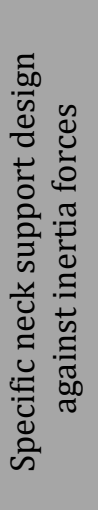 & 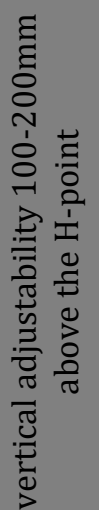 & 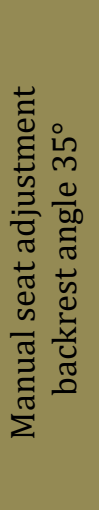 & 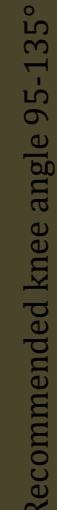 \\
\hline $\begin{array}{c}\text { Provide a dynamic and regular } \\
\text { adjustability of the Backrest angle when } \\
\text { driving }\end{array}$ & $x$ & & & & & & & \\
\hline $\begin{array}{l}\text { Provide a dynamic and regular } \\
\text { adjustability of the Lumbar support } \\
\text { prominence WD }\end{array}$ & & $x$ & & & & & & \\
\hline $\begin{array}{l}\text { Less effort exposure while controlling } \\
\text { the vehicle speed }\end{array}$ & & & $x$ & & & & & \\
\hline $\begin{array}{c}\text { Decrease the exposure to inertia forces } \\
\text { on the body }\end{array}$ & & & & $x$ & & & & \\
\hline $\begin{array}{c}\text { Decrease the exposure to inertia forces } \\
\text { on the neck }\end{array}$ & & & & & $x$ & & & \\
\hline $\begin{array}{l}\text { Adjust the vertical position of the } \\
\text { lumbar support }\end{array}$ & & & & & & $\mathbf{x}$ & & \\
\hline Satisfy the easy reach to steering wheel & $x$ & & & & & & $x$ & \\
\hline Satisfy the easy reach to pedals & $x$ & & & & & & & $x$ \\
\hline Technical Priorities & A & B & C & D & $\mathbf{E}$ & $\mathbf{F}$ & G & $\mathbf{H}$ \\
\hline
\end{tabular}

Table2: The House of Quality.

The following design matrix (e) is a triangular matrix. The design happens to be a decoupled design and the independence axiom is satisfied.

$$
\left\{\begin{array}{l}
F R_{111} \\
F R_{112} \\
F R_{121} \\
F R_{122} \\
F R_{123} \\
F R_{131} \\
F R_{141} \\
F R_{142}
\end{array}\right\}=\left[\begin{array}{llllllll}
1 & 0 & 0 & 0 & 0 & 0 & 0 & 0 \\
0 & 1 & 0 & 0 & 0 & 0 & 0 & 0 \\
0 & 0 & 1 & 0 & 0 & 0 & 0 & 0 \\
0 & 0 & 0 & 1 & 0 & 0 & 0 & 0 \\
0 & 0 & 0 & 0 & 1 & 0 & 0 & 0 \\
0 & 0 & 0 & 0 & 0 & 1 & 0 & 0 \\
1 & 0 & 0 & 0 & 0 & 0 & 1 & 0 \\
1 & 0 & 0 & 0 & 0 & 0 & 0 & 1
\end{array}\right]\left\{\begin{array}{l}
D P_{111} \\
D P_{112} \\
D P_{121} \\
D P_{122} \\
D P_{123} \\
D P_{131} \\
D P_{141} \\
D P_{142}
\end{array}\right\}(\mathrm{e})
$$

The movement frequency changes over time these casements are related to the type of the car seat and to the task being executed. Nevertheless, the question that should be asked; how should the car seat get to know what it should adapt to? In other words, the car seat should be aware of the car's interior environment, on the one hand, and of the person sitting in it and his or her current task, on the other hand, to stimulate the user to move when he or she has been sitting still too long. Unfortunately, the drivers must maintain a static position due to the particular limitations of the car seat and activities such as seat belt use and the great visual effort, 
offering less possibilities of making significant postural changes (Figure 9). Thus to prevent musculoskeletal disorders the seat will allow more dynamic movement while the user performed the ordinal driving task. The required tasks and the car seat design were explored in several scenarios. These scenarios were translated into design concepts and discussed with users and experts. Figures 9a through 9c show some concept drawings.

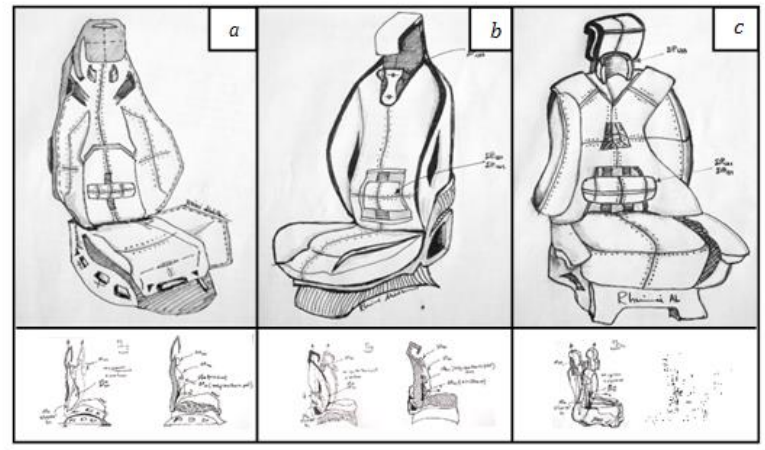

Figure 9: Concept drawings of the Car Seat design.

\section{Discussion}

The conclusion from the exploratory study is that there are possibilities for letting the car seat react to the driver's emotional state. This feature could be used to reduce musculoskeletal disorders. Reducing discomfort in itself is important, but knowing that data on discomfort can prevent musculoskeletal injuries in the future; strengthens its importance. The strength of the participatory approach will be used in the further article (Part II) were the evaluation process will be made by the end users [15].

\section{Conclusion}

The study found that the major drivers who work intensively on vehicles suffer from back pain, heavy foot, and joint locking after the driving task. According to participants, the physiological aspect is the most important feature of the discomfort generated in a driving task. In addition, the low back pain had the highest discomfort rating among participants and the major reason for the physiological discomfort is the static position. Reducing the discomfort generated by the PSP in a sitting posture was the objective of this paper; it has been shown that a design based on ergonomics principals by using both participatory and axiomatic design approaches, can satisfy the desired objective. A reduction of symptoms of the static position is a state that should be achieved when the design parameters of the seat is able to address the needs, ability and limitations of the user. Moreover, this goal could not be achieved without dealing with users. In the Selection of improvement and design section, a new design of the car seat was suggested to reduce the problem, knowing that the human being's natural behavior is to change posture frequently. The seat posture is determined by both the design of the seat and the task to be performed. The Next paper will accomplish the work introduce in this article and conclude the last three steps of participatory design approach where the goal is to introduce an objective evaluation of the design suggested.

\section{Acknowledgement}

The authors gratefully acknowledge the financial assistance provided by the National Center of Scientific Research and Technology "CNRST", Grateful thanks goes also to Professor Mouncif Sidki.

\section{References}

1. Eifell RK, Ashour HY, Heslop PS, Walker DJ, Lees Ta (2006) Association of 24-hour activity levels with the clinical severity of chronic venous disease. Journal of Vascular Surgery 44(3): 580-587.

2. Élias R, Tisserand M, Christmann H, Schouller JF, Boitel L (1981) Étude ergonomique du poste de travail de caissière de libre- service. Cahiers de notes documentaires-Sécurité et hygiène du travail 1(3): 211-220.

3. Magora A (1972) Investigating of the relation between low back pain and occupations. 3. Physical requirements: sitting, standing and weight lifting. IMS Ind Med Surg 41(12): 5-9.

4. Wilke HJ, Neef P, Caimi M, Hoogland T, Claes LE (1999) New in vivo measurements of pressures in the intervertebral disc in daily life. Spine 24(8): 755-762.

5. McGill SM, Brown S (1992) Creep response of the lumbar spine to prolonged full flexion. Clin Biomech (Bristol, Avon) 7(1): 43-46.

6. Solomonow M (2004) Ligaments: a source of workrelated musculoskeletal disorders. J Electromyogr Kinesiol 14(1): 49-60. 
7. Keegan JJ, Nebraska O (1953) Alteration of the lumbar curvature related to posture and seating. Bone and Joint Surgery 35(3): 589-603.

8. Suh NP (2007) Ergonomics, axiomatic design and complexity theory. Theoretical Issues in Ergonomics Science 8(2): 101-121.

9. Vink P (2002) Comfort, Delft: Delft University of Technology (inaugural address).

10. Vink PN, Davies RC (2005) Participatory ergonomics and comfort. In: Vink P (Ed.), Comfort and Design principals and good practice, Crc Press, Boca Raton.

11. Suh NP (2001) Axiomatic Design: Advances and Application. Oxford University Press, Inc, New York.

12. National Academy of Engineering (2002) Approaches to Improve Engineering Design.

13. Vink P, Kompier MAJ (1997) Improving office work: A participatory ergonomic experiment in a naturalistic setting. Ergonomics 40(4): 435-449.

14. Noro K, Imada A (1991) Participatory Ergonomics, Taylor \& Francis, London.

15. Rhimi A (2017) Concepts for the reduction of the discomfort generated by the prolonged static posture during the driving task, part II: Experiments and validations. International Journal of Industrial Ergonomics 57: 55-62.

16. Valdeon S, Fernando F, André O (2001) Axiomatic Approach Application during the Product Conceptual Design Phase. International Conference "MECHANIKA 2001”. Kaunas, Lithuania, PP: 267-272.

17. Kelsey JL, Hardy RJ (1975) Driving of motor vehicles as a risk factor for acute herniated lumbar intervertebral discs. American Journal of Epidemiology 102(1): 63-73.

18. Sudoł-Szopińska (2006) Influence prolonged sedentary work on the development of lower limbs edema and methods of its prevention. Medycyna Pracy 57(3): 263-269.

19. Winkel J, Bendix $\mathrm{T}$ (1986) Muscular performance during seated work evaluated by two different EMG methods. Eur J Appl Physiol 55(2): 167-173.
20. Pottier M, Dubreuil A, Monod H (1969) The effect of sitting posture on the volume of the foot. Ergonomics 12(5): 753-758.

21. Sun JM (1990) Epidemiologic study on peripheral vascular disease in Shanghai. Zhonghua Wai Ke Za Zhi 28(8): 480-483.

22. Weddell IM (1969) Varicose veins pilot survey. British Journal of Preventative and Social Medicine 23(3): 179-186.

23. Winkel J, Jorgenson K, Noddeland H (1988) International ergonomics association, 10th International congress, 1-5 August, Sydney Australia.

24. Keegan JJ (1962) Evaluation and improve of seats. Industrial Medicine and Surgery 31: 137-148.

25. Van Dieën JH, Nussbaum MA (2004) Trunk. In: Working postures and movements: Tools for evaluation and engineering. In: Delleman NJ, Haslegrave CM, Chaffin DB (Eds.), Boca Raton, FL, USA, pp: 109-141.

26. Vergara M, Page A (2002) Relationship between comfort and back posture and mobility in sitting posture. Applied Ergonomics 33(1): 1-8.

27. Ferguson 0 (1976) Posture aching and body build in telephonists. Journal of Human Ergology 5(2): 183186.

28. Hünting W, Grandjean E, Maeda K (1980) Constrained postures in accounting machine operators. Applied Ergonomics 11(3): 145-149.

29. Rebiffé R (1969) Seat of the driver: it's adaptation to functional and anthropometric requirements. Ergonomics 12(2): 246-261.

30. Andersson BJ, Ortengren R, Nachemson A, Elfström G (1974b) Lumbar disc pressure and myoelectric back muscle activity during sitting. IV. Studies on a car driver's seat. Scand J Rehabil Med 6(3): 128-133.

31. Reed MP, Saito M, Kakishima Y, Lee NS, Schneider LW (1991) An investigation of driver discomfort and related seat design factors in extended-duration driving. SAE Technical Paper, PA: Society of Automotive Engineers, Inc., Warrendale.

32. Reed MP, Schneider LW, Saito M, Kakishima Y, Lee NS (1991) An investigation of automotive seating 
discomfort and seat design factors. Final re-port (UMTRI-91-11), Ann Arbor, MI: University of Michigan Transportation Research Institute.

33. Matthew P Reed, Lawrence W Schneider, Leda L Ricci (1994) Survey of auto seat design recommendations for improved comfort. Technical report (umtri-94-6),
Ann Arbor, university of michigan transportation research institute.

34. Stokes IA, Abery JM (1980) Influence of the hamstring muscles on lumbar spine curvature in sitting. Spine 5(6): 525-528. 